\title{
In Vitro Monitoring of Surface Mechanical Properties of Poly(L-Lactic Acid) Using Microhardness
}

\author{
C. Saiz-Arroyo, ${ }^{1,2}$ Y. Wang, ${ }^{1,2}$ M. A. Rodriguez-Perez, ${ }^{3}$ N. M. Alves, ${ }^{1,2}$ J. F. Mano ${ }^{1,2}$ \\ ${ }^{1}$ Polymer Engineering Department, University of Minho, Campus of Azurém, 4800-058 Guimarães, Portugal \\ ${ }^{2} 3 B^{\prime}$ s Research Group - Biomaterials, Biodegradables and Biomimetics, University of Minho, 4710-057 Braga, Portugal \\ ${ }^{3}$ Department of Condensed Matter Physics, University of Valladolid, E-47011 Valladolid, Spain
}

Received 17 March 2006; accepted 4 April 2007

DOI 10.1002/app.26705

Published online 11 June 2007 in Wiley InterScience (www.interscience.wiley.com).

\begin{abstract}
Poly(L-lactic acid) (PLLA) was immersed in a simulated body fluid (SBF) solution at $37.5^{\circ} \mathrm{C}$ for distinct times. The variation of the surface mechanical properties of PLLA samples with immersion time was followed by microhardness. These measurements showed that PLLA microhardness decreased significantly $(\sim 60 \%)$ after only 30 days of immersion. The results were explained in terms of hydrolytic degradation of the samples. The dependence of microhardness with the applied dwell time was also analyzed. The creep curves were successfully described by a power law. A decrease of the creep constant $k$ as the immersion time increased was found. Differential scanning
\end{abstract}

calorimetry was also used to analyze the changes in the physical properties of PLLA, namely in crystallinity degree $\left(X_{c}\right)$ and glass transition temperature $\left(T_{g}\right)$, as a function of the immersion time in SBF. A significant variation in the crystallinity degree of PLLA, initially nearly amorphous $\left(X_{c}=9 \%\right)$, was detected after only 3 days of immersion $\left(X_{c}=37 \%\right)$. The interpretation of this behavior was based on the hydrolysis process suffered by PLLA. (c) 2007 Wiley Periodicals, Inc. J Appl Polym Sci 105: 3858-3864, 2007

Key words: indentation; hardness; biodegradable; biomaterials; crystallinity

\section{INTRODUCTION}

Poly(L-lactic acid) (PLLA) has been widely studied for use in biomedical applications due to its biocompatibility and bioresorbability. These biomedical applications include sutures, scaffolds for tissue engineering, orthopaedic devices, or drug delivery systems. ${ }^{1-6}$ Moreover, when implanted in the human body, PLLA degrades, primarily by hydrolysis. ${ }^{7}$ The hydrolytic degradation of PLLA during implantation is followed by a change of the physical properties of the material. This is particularly important for orthopaedic implants, where a compromise between mechanical performance and degradation behavior must exist and the continuous decrease of the mechanical properties should be compensated by the remodeling of bone. Also, ideally the products of degradation should be readily absorbed under normal metabolic conditions. The degradation process ultimately ends with the total resorption of the polymer. ${ }^{8}$

Microhardness is a simple but informative technique that has been used to determine changes in morphology and microstructure of polymers, ${ }^{9,10}$ variations with

Correspondence to: J. F. Mano (jmano@dep.uminho.pt).

Contract grant sponsor: FCT; contract grant numbers: POCTI/FIS/61621/2004, SFRH/BPD/11497/2002.

Journal of Applied Polymer Science, Vol. 105, 3858-3864 (2007) C 2007 Wiley Periodicals, Inc.

\section{(\$)WILY}

InterScience molecular orientation ${ }^{11}$ or, in polymer blends/composites, with composition. ${ }^{12,13}$ It also gives information about several bulk properties such as yield stress or elastic modulus. ${ }^{14}$ Several microhardness studies related to high crystallinity degree polymers ${ }^{15,16}$ can be found in literature, but regarding polymers with low crystallinity degree, such as PLLA, the literature is more scarce ${ }^{9,17,18}$ and focuses specially on poly(ethylene terephthalate).

In a biomedical point of view, microhardness measurements have been often used to probe changes in the mechanical behavior of bone and biomaterials. ${ }^{19-21}$ Moreover, biomaterials interact with their environment at the cellular level and it is the surface of the material that directly interacts with proteins and cells. ${ }^{22-24}$ Consequently, the surface mechanical properties of an implant are very important on determining cell responses ${ }^{22,23}$ and the implant behavior will deeply depend on these properties. ${ }^{24}$ Microhardness tests can provide a possible way to determine the actual hardness of the surface layer, which is difficult to measure by traditional techniques, such as tensile or flexural tests. Also, this kind of experiments only measures the mechanical properties of the bulk and cannot detect local variations in these properties as microhardness can.

The aim of the present work is to make an in vitro analysis of the variation of the surface mechanical properties of PLLA immersed in a simulated body fluid (SBF) solution at $37.5^{\circ} \mathrm{C}$ for distinct times, by 
microhardness. When PLLA is kept at the aforementioned conditions we are roughly simulating the degradation conditions in the human body. Some microhardness data of PLLA can be found in literature, ${ }^{5,25,26}$ but these studies only measure the microhardness of nondegraded samples.

It has been reported that the hydrolytic degradation also affects the crystallinity of PLLA-based systems. ${ }^{27}$ In this work differential scanning calorimetry (DSC) is used to analyze and evaluate the changes in the physical properties of PLLA, namely in the degree of crystallinity and glass transition temperature, as a function of the immersion time in SBF, thus complementing microhardness results. It should be mentioned that recently a nanoindentation/degradation study on PLA-based systems was made, ${ }^{28}$ but the relationship between crystallinity and surface mechanical properties was not explored.

\section{EXPERIMENTAL}

The PLLA used in this work was PLA4040 from Cargill-Dow, with 94\% L-lactide. The molecular weight evaluated from GPC was $M_{n}=69,000$, being $M_{w} / M_{n}=1.72$.

PLLA plates were prepared by compression molding using the following procedure: PLA granules were placed between two metallic discs with a diameter of $30 \mathrm{~mm}$ and heated until a temperature higher than its melting temperature was reached, in this case $180^{\circ} \mathrm{C}$. Then, a constant compression load was applied during $4 \mathrm{~min}$. After the previous step the samples were rapidly cooled using cold water, and therefore, the plates were obtained as nearly amorphous materials (the crystallinity degree $\left(X_{c}\right)$ measured by DSC was 9\%).

After cooling, the samples were kept at $75^{\circ} \mathrm{C}$ for $5 \mathrm{~min}$ to erase the thermal history and then were immersed for different periods of time $(0,1,3,5$, $10,16,20,25$, and 30 days) at $37.5^{\circ} \mathrm{C}$ in a SBF solution. This fluid has ion concentrations nearly equal to those of human blood plasma and it has been used to probe the ability of a material to induce the formation of an apatite coating. ${ }^{29}$ Three samples, with dimensions of $\sim 3 \mathrm{~mm} \times 10 \mathrm{~mm} \times 10$ $\mathrm{mm}$, were used for each time point. Surface mechanical properties of PLLA samples before and after its immersion in a SBF solution were studied by microhardness.

A Leica VMHT30 equipment was used to measure the microhardness of the samples at room temperature $\left(\sim 20^{\circ} \mathrm{C}\right)$, using a Vickers diamond pyramid indenter (included angle $\alpha=136^{\circ}$ ). The microhardness, $H$, was calculated from the residual projected diagonal impression using $H=1.854$ $F / d^{2}$, where $d$ is the mean diagonal length of the indentation in $\mathrm{mm}$ and $F$ the applied force in $\mathrm{N}$. To evaluate the dependence of $H$ with time and load, measurements were made for five dwell times $(10,20,30,60$, and $90 \mathrm{~s})$ and using for each time three indentation loads: 9.807, 49.03, and $98.07 \mathrm{mN}$. The length of the resulting indentation was measured immediately after load release, to avoid complications associated with viscoelastic recovery. At least five imprints were made on each test at randomly chosen places of the samples. The indentation depth corresponding to these measurements varied between 1 and $2 \mu \mathrm{m}$.

A Perkin-Elmer DSC7 differential scanning calorimeter with a controlled cooling accessory was used to perform DSC experiments on the PLLA samples analyzed by microhardness. Two consecutive scans at $10^{\circ} \mathrm{C} / \mathrm{min}$ from 30 to $190^{\circ} \mathrm{C}$ were performed on each PLLA sample (with a typical weight of $\sim 10 \mathrm{mg}$ ) previously immersed in SBF for the different periods mentioned earlier. Between the first and the second scans all the samples were cooled from 190 to $30^{\circ} \mathrm{C}$ at the same rate $\left(40^{\circ} \mathrm{C}\right.$ / $\mathrm{min}$ ). The temperature of the equipment was previously calibrated with Indium and Lead standards and only the same Indium sample was used for the heat flow calibration. The calibrations were performed during heating at $10^{\circ} \mathrm{C} / \mathrm{min}$.

\section{RESULTS AND DISCUSSION}

\section{Microhardness results}

In this study, different microhardness tests were performed with PLLA to evaluate the changes when the polymer degrades by being immersed in an aqueous medium for distinct periods of time. In these measurements, presented in Figure 1, different dwell times and forces were used.

When the dwell time is fixed, it can be seen that the measured hardness is load dependent, for all the dwell times. This is valid for both nonimmersed and immersed samples. When the load is fixed, $H$ typically decreases with increasing dwell time, ${ }^{14}$ as seen in Figure 1 for the PLLA samples due to the creep effect shown by polymeric materials, ${ }^{14}$ i.e., to the time-dependent strain response to a constant applied force. The creep behavior in polymers has been widely described by a power law. ${ }^{30}$ The creep strain is considered to consist of three independent components: an elastic strain, a recoverable strain, and a nonrecoverable plastic strain. A power law can predict the continuous decrease of the strain rate observed in conventional creep experiments ${ }^{30}$ and it has also been assumed that this kind of model could predict the creep effect when it is evaluated through microhardness experiments. ${ }^{14}$ In fact, the creep 

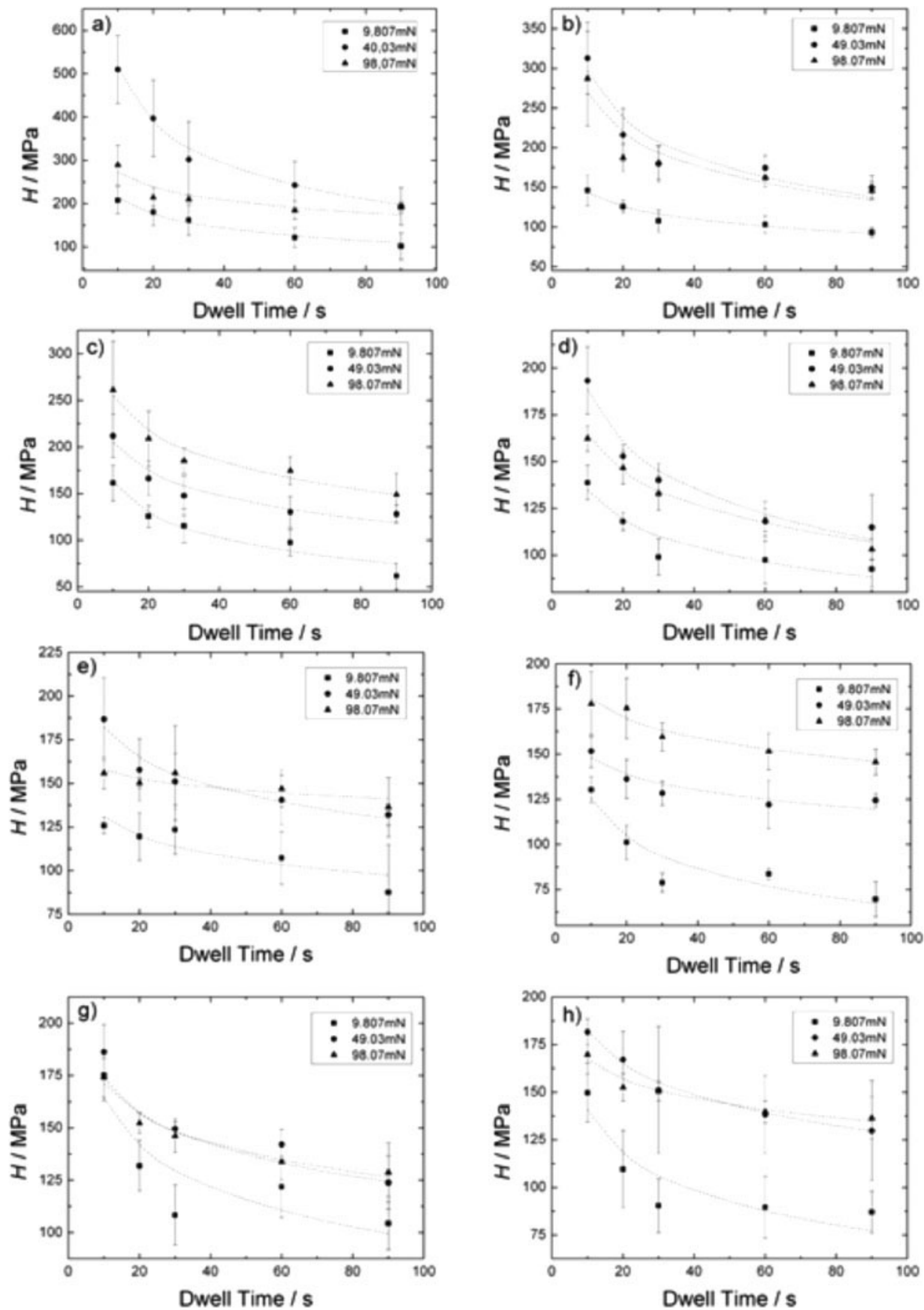

Figure 1 Microhardness against dwell time for three different forces (indicated in the graphics), measured after PLLA being immersed during distinct times: (a) 0 days, (b) 1 day, (c) 5 days, (d) 10 days, (e) 16 days, (f) 20 days, (g) 25 days, and (h) 30 days. 


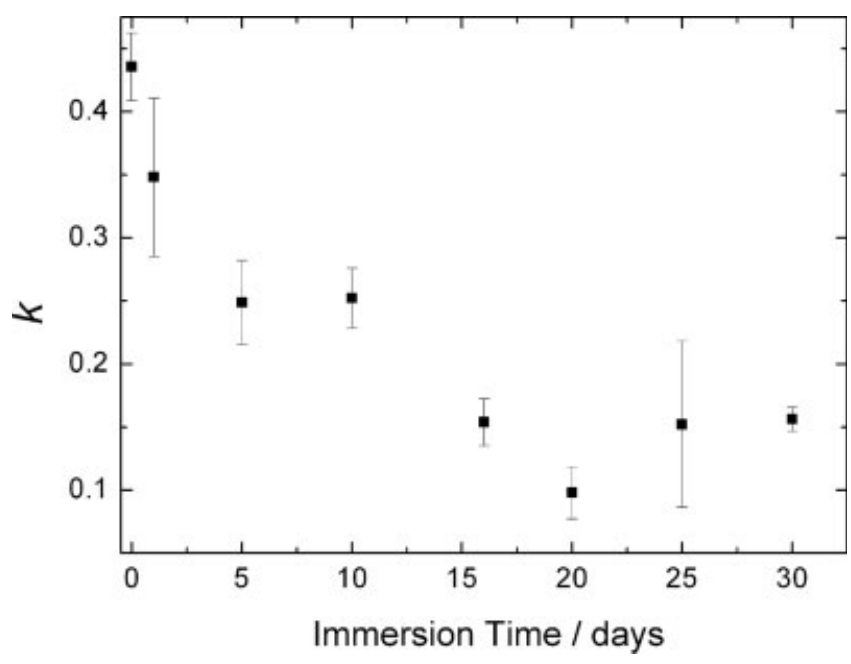

Figure 2 Variation of the creep constant with immersion time for the applied force of $49.03 \mathrm{mN}$.

curves of Figure 1 were successfully described by the following power law:

$$
H=H_{0} t^{-k}
$$

where $H_{0}$ is a coefficient that, for a given morphology, depends on temperature and loading stress, $k$ gives a measure of the creep rate of the material, and $t$ is the dwell time.

The creep constant $k$ was calculated from the previous data, using a conventional nonlinear least square curve fitting algorithm. Figure 2 shows the dependence of $k$ with immersion time for the force of $49.03 \mathrm{mN}$. It can be observed how $k$ tends to decrease as the immersion time increases. In this case, the creep rate decreases about $67 \%$ for an immersion period of 30 days. The same behavior was found for the other applied forces (not shown).

When PLLA has not been immersed in SBF, $H$ varies between 500 and $200 \mathrm{MPa}$ (dwell time $=10 \mathrm{~s}$ ), which are typical values for polyesters. ${ }^{14}$ Also, a previous work ${ }^{25}$ showed that the microhardness of the same PLLA samples studied in this work, but nonimmersed, may increase more than $55 \%$ after 15 days at body temperature, due to physical ageing. For this specific PLLA microhardness changed from 130 to $210 \mathrm{MPa}$. However, when microhardness is represented as a function of immersion time (Fig. 3) it can be observed that it decreases as the immersion time increases. This behavior is again more evident for the intermediate load. In this case $H$ may decrease as much as $\sim 60 \%$ after being immersed 30 days. The same tendency was found for the other forces (not shown). So, the significant decrease in microhardness found when PLLA is immersed cannot be attributed to physical ageing, otherwise we would observe an opposite variation, as already explained in Ref. 25. Moreover, these results pro- vide evidences for a significant variation of the mechanical behavior after immersion, which could affect the performance of an implanted PLLAbased biomaterial.

The considerable decrease of the surface hardness with increasing immersion time can be explained by PLLA degradation. It is well known that PLLA degrades primarily by hydrolysis, and that the degradation occurs in two stages. ${ }^{31}$ First, a random nonenzymatic chain scission of the ester groups occurs. Second, low molecular weight PLLA can diffuse out of the bulk polymer and the molecular weight is reduced in in vivo conditions until the lactic acid and low molecular weight oligomers are naturally metabolized by microorganisms to yield carbon dioxide and water. ${ }^{31}$

It is not straightforward to compare our results with other PLLA results from literature because the samples have different molecular weights, crystallinities, general morphology, or sizes. However, the general conclusion in literature is that only small changes are seen in strength and modulus for periods up to 12 weeks in vitro, ${ }^{32,33}$ as the techniques employed only measure the properties of the bulk. The microhardness technique used in this work allows to measure the variations in the surface mechanical properties of PLLA and, therefore, these changes can be detected much earlier because the hydrolysis process generally starts at the sample surface. ${ }^{5,31,34}$ Recently, a nanoindentation/degradation study on PLA-based systems also allowed detecting variations in mechanical properties earlier (after 4 weeks) than traditional tests. ${ }^{28}$ However, in the referred study, no measurements of crystallinity were performed and related to the variations of surface mechanical properties as in our work (see next section). It should be mentioned that although it is generally

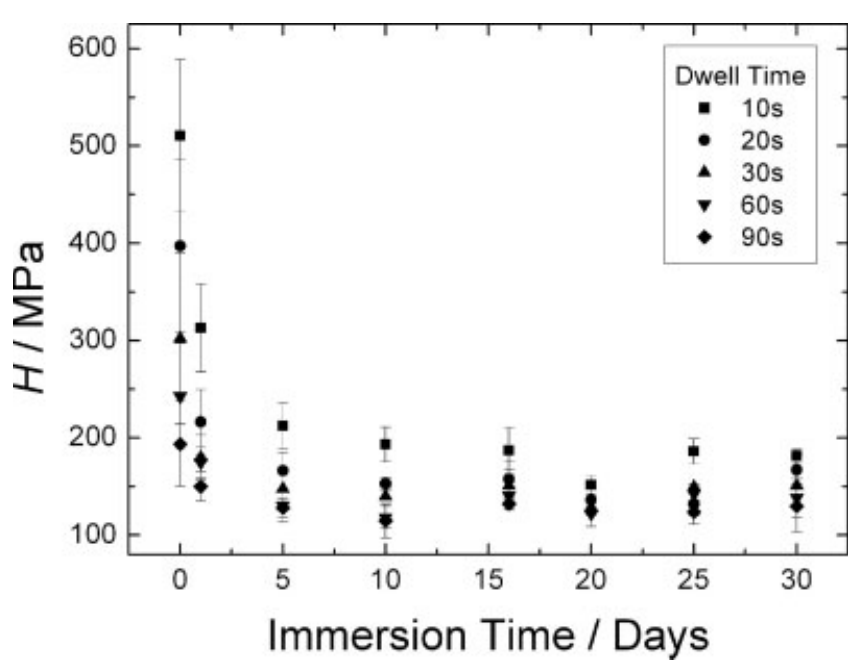

Figure 3 Microhardness against immersion time for the applied force of $49.03 \mathrm{mN}$. The distinct dwell times used are indicated in the graphics. 


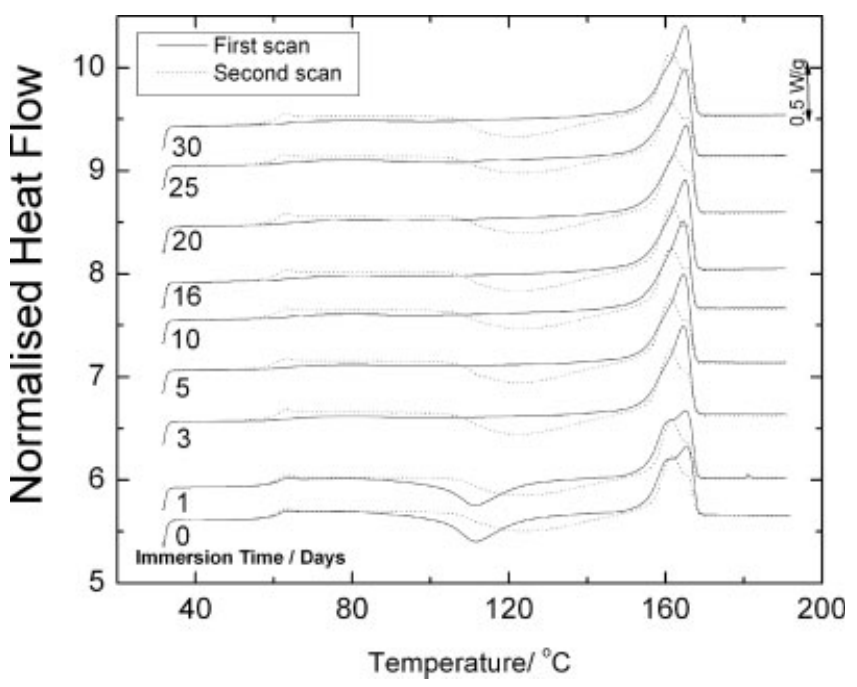

Figure 4 Temperature dependence of the normalized heat flow measured in heating DSC scans at $10^{\circ} \mathrm{C} / \mathrm{min}$, after PLLA being immersed during distinct times (indicated in the graphics). All the samples were subjected to two consecutive scans. Between the first and the second scans all the samples were cooled from 190 to $30^{\circ} \mathrm{C}$ at $40^{\circ} \mathrm{C} / \mathrm{min}$.

accepted that the beginning of degradation occurs principally at the surface because of the absorption gradient of water, the evolution of this process has been explained either via a bulk erosion mechanism, starting at the surface and then gradually proceeding towards the inner side, ${ }^{5,31,35}$ or as a heterogeneous process, ${ }^{34}$ being more rapid in the center than at the surface as the concentration of carbonyl groups increases in the center, because these act as catalysts for the process, i.e., the oligomers trapped in the core have a catalytic effect on degradation. ${ }^{34}$

Typically, PLLA undergoes a considerable weight loss only after being immersed for several months. ${ }^{31,36,37}$ However, it is also known that the hydrolytic degradation rate of PLLA is mainly affected by molecular weight, crystallinity, morphology and type of chain orientation, particle size and shape of the implanted device, and residual lactic acid concentration. ${ }^{31}$ For instance, some authors report a slower degradation of PLLA as molecular weight increases ${ }^{35,38}$ or when the crystallinity degree of PLLA decreases. ${ }^{27,31}$ In the aforementioned works ${ }^{31,36,37}$ the studied PLLAs have higher molecular weights and high crystallinity degrees than the PLLA used in this work, which has a low molecular weight and it is a nearly amorphous material before immersion, and so it is expected a higher degradation rate than in the referred studies.

\section{DSC results}

DSC scans were conducted on PLLA samples as a function of immersion time to evaluate the corre- sponding changes in the glass transition and crystallinity (Fig. 4). The first scan of the nonimmersed sample exhibited a glass transition temperature $T_{g}$ at $\approx 59^{\circ} \mathrm{C}$ and a well-pronounced cold crystallization peak. This indicates that initially this sample should have a low amount of crystallinity. After 3 days of immersion the cold crystallization peak is absent and the glass transition temperature is less pronounced. The $X_{c}$ and $T_{g}$ values calculated from the results of Figure 4 (first scan) are presented in Figure 5. $X_{c}$ can be estimated from DSC using the following equation:

$$
X_{c}=\frac{\Delta H_{m}-\Delta H_{c}}{\Delta H_{m}^{0}}
$$

where $\Delta H_{m}$ is the measured enthalpy of fusion, $\Delta H_{m}^{0}$ is the enthalpy of fusion of the completely crystalline material $\left(93.7 \mathrm{~J} / \mathrm{g}\right.$ for $\left.\mathrm{PLLA}^{39}\right)$, and $\Delta H_{c}$ is the enthalpy of cold crystallization observed during the run.

Figure 5 shows that after 3 days of immersion there is a significant increase in $X_{c}(\sim 37 \%)$, which was just $\sim 9 \%$ before immersion. From 3 to 5 days, $X_{c}$ suffers a slight increase $\left(X_{c} \sim 40 \%\right)$. Changing the time from 5 to 30 days did not affect $X_{c}$ significantly, i.e., after 5 days the sample reaches almost its maximum crystallinity.

Several works showed that PLLA crystallinity increases as a result of hydrolytic degradation $^{27,35,38,40-42}$ - this is the so-called "degradationinduced crystallization." ${ }^{\prime 37,38,40-43}$ Also, the higher the initial or the increased crystallinities in the degradation process become, the more the degradation rate accompanied by the hydrolysis of PLLA would be suppressed. This happens because the amorphous phase would be hydrolyzed before the crystalline one. ${ }^{27,35,38,40-42}$ So, a PLLA with initial higher crystal-

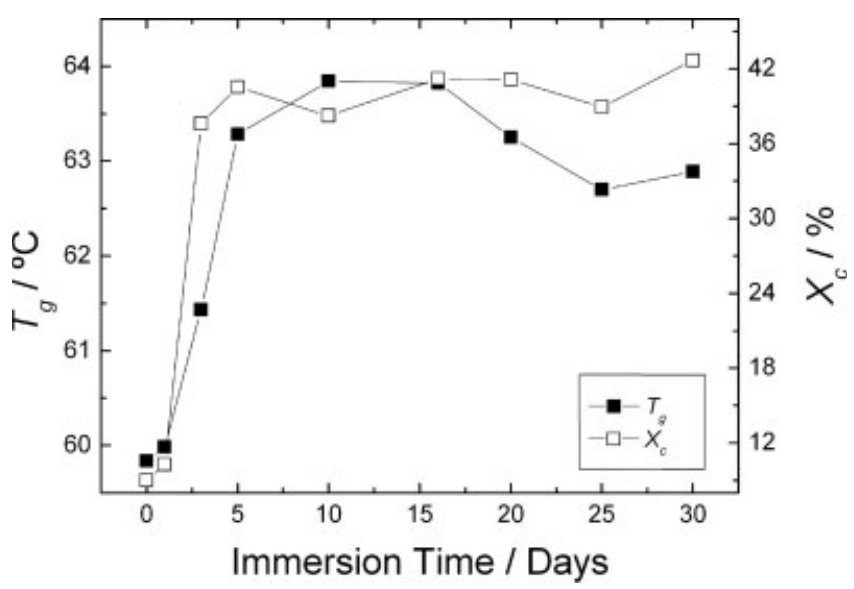

Figure 5 Glass transition temperature $\left(T_{g}\right)$ and degree of crystallinity $\left(X_{c}\right)$ of PLLA as a function of immersion time. $T_{g}$ and $X_{c}$ were calculated from the data of first DSC runs depicted in Figure 4. 
linity would have lower degradation and crystallization rates.

Our results are in agreement with the previously reported works, ${ }^{27,35,38,40-42}$ i.e., as the sample has initially a very low crystallinity degree the crystallization rate is high and, in this case, in a short immersion period occurs a change in the crystallinity degree from 9 to $37 \%$. Such a dramatic increase may seem unexpected. However, other examples of significant increase in PLLA crystallinity for short periods of in vitro degradation can be found in literature, which support our results. ${ }^{38,41,42}$

The degradation-induced crystallization $37,38,40-43$ has been mainly explained in terms of a rearrangement of the shorter chains generated by the degradation process itself, along with the consequent formation of new crystals, although some believe that the degradation of the amorphous part of the polymer merely results in a larger percentage of crystalline phase being left. We think that the first interpretation presented earlier explains the behavior on the early stages of degradation, i.e., the amorphous regions crystallize. It is not probable that a significant amount of water-soluble oligomers formed by the hydrolysis of the amorphous regions has been released from the PLLA sample into the surrounding medium only after 3 days of immersion, to originate such a high increase in $X_{c}$ as the second interpretation implies. As You et al. suggested, the tie chains in the amorphous regions could degrade into fragments and this results in a lesser degree of entanglements by the long-chain molecules in the amorphous regions that may, therefore, form new crystalline regions. ${ }^{42}$

The $T_{g}$ of PLLA also increases $\sim 3.5^{\circ} \mathrm{C}$ after an immersion time of 5 days and then tends to stabilize. This variation is directly related to the corresponding variation of $X_{c}$ : the amorphous regions of a sample with higher crystallinity have a more restricted conformational mobility and then $T_{g}$ increases. This effect was discussed in more detail for PLLA elsewhere. ${ }^{44}$ The increase of the specific heat capacity at the glass transition, $\Delta C_{p}\left(T_{g}\right)$, is a measure of the amorphous fraction. As expected, we observed a decrease of $\Delta C_{p}\left(T_{g}\right)$ with increasing immersion time. Moreover, the strong coupling between the crystalline and amorphous phases also results in a broadening of the glass transition, as typically seen in other semicrystalline polymers. ${ }^{45,46}$

Regarding the second scans of the samples (Fig. 4), variations in the values of the glass transition temperature and/or the melting temperature would be expected to be measured by DSC if the molecular weight of the PLLA samples decreased significantly due to degradation. However, no significant differences were found in the second scans even when the scan of the sample that was not immersed is com- pared with the scan of the sample immersed for 30 days.

The DSC results can be related with the microhardness results presented in the Microhardness results section. For semicrystalline polymers the increase of $H$ with annealing time at a constant annealing temperature has been explained in terms of crystallinity and crystalline lamellar thickness changes. ${ }^{14}$ Typically, $H$ suffers an increase when $X_{c}$ increases. ${ }^{14}$ However, the obtained results (Figs. 3 and 5) show the opposite behavior. As crystallinity increases it could be expected a temporary increase in the mechanical properties, at least at the first stages of degradation. This could occur, if we were measuring the mechanical properties of the bulk, but, as discussed in the Microhardness results section, the microhardness measurements reflect the surface hardness that decreases because the degradation itself starts at the surface. Other effect that may also contribute to the decrease of surface hardness could be the water uptake, although it is known that PLLA is quite hydrophobic and the amount of water absorbed after 30 days should be low, ${ }^{31}$ as our DSC results suggest. In fact, if a significant amount of water is absorbed by a material its $T_{g}$ will decrease due to the plasticizer effect of water. However, as previously mentioned, we did not find a decrease in $T_{g}$ with increasing immersion time (see Fig. 5).

The creep constant $k$ obtained by microhardness measurements has been shown to depend on crystallization temperature and annealing effects. ${ }^{14}$ Moreover, $k$ is a measure of the creep rate and should decrease when the crystallinity of the sample increases. ${ }^{14}$ Our results (Figs. 2 and 5) also show a decrease in $k$ as $X_{c}$ increases.

\section{CONCLUSIONS}

The microhardness measurements conducted on PLLA plates immersed in SBF at $37.5^{\circ} \mathrm{C}$ from 1 to 30 days allowed to make an in-vitro analysis of the surface mechanical properties of the samples. The main conclusions of this study are now summarized:

1. It was found that the measured microhardness was load dependent, both for immersed and nonimmersed samples. For a given load, microhardness decreased with increasing dwell time. The creep curves were characterized by a decreasing strain rate and successfully described by the power law $H=H_{0} t^{-k}$. The creep constant $k$, a measure of the creep rate of the material, decreased as the immersion time increased. A high decrease in $k$ was measured $(\sim 67 \%)$ after an immersion period of 30 days. 
2. The microhardness decreased with increasing immersion time. After 30 days microhardness decreased $\sim 60 \%$. These results provide evidences for a significant variation in the mechanical behavior that could affect the performance of an implanted PLLA-based biomaterial. This decrease was explained by hydrolytic degradation.

3. Microhardness was applied for characterizing the degradation of polylactide-based biomaterials. It was shown that this technique is an adequate method to monitor the mechanical properties at the surface of biomaterials that could be useful to predict the mechanical performance of an implant in contact with the tissue.

4. The main advantage of microhardness, when compared with other techniques that only measure the bulk properties, is that it measures the variations in the surface mechanical properties and these changes can be detected much earlier than with the aforementioned techniques when the sample degrades mainly by hydrolysis, because this process typically starts at the surface of the sample.

Regarding the DSC results the main feature was the significant increase in the crystallinity degree of PLLA from 9 to $37 \%$ after only 3 days of immersion in SBF. This degradation induced crystallization was explained in terms of a rearrangement of shorter chains generated by the hydrolytic scission of the ester links. The high crystallization rate was attributed mainly to the initially low crystallinity degree of PLLA. The increase of $T_{g}\left(\sim 3.5^{\circ} \mathrm{C}\right)$ after the sample being immersed was related with the corresponding increase in the crystallinity degree. Although the crystallinity degree increased with increasing degradation time, the opposite variation was found for microhardness, because this property is a measure of the surface mechanical properties of PLLA, which are getting poorer as the immersion time in SBF increases.

\section{References}

1. Thomson, R. C.; Wake, M. C.; Yaszemski, M. J.; Mikos, A. G. Adv Polym Sci 1995, 122, 245.

2. Agrawal, C. M.; Ray, R. B. J Biomed Mater Res 2001, 55, 141.

3. Södegard, A.; Stolt, M. Prog Polym Sci 2002, 27, 1123.

4. Kim, H. D.; Bae, E. H.; Kwon, I. C.; Pal, R. R.; Nam, J. D.; Lee, D. S. Biomaterials 2004, 25, 2319.

5. Shikinami, Y.; Okuno, M. Biomaterials 1999, 20, 859.

6. Majola, A.; Vainionpaa, S.; Rokkanen, P.; Mikkola, H. M.; Tormala, P. J Mater Sci Mater Med 1992, 3, 43.

7. Sodergard, D.; Stolt, M. Prog Polym Sci 2002, 27, 1123.

8. Claes, L. E. Clin Mater 1992, 10, 41.

9. Santa Cruz, C.; Baltá Calleja, F. J.; Zachmann, H. G.; Stribeck, N.; Asano, T. J Polym Sci Part B: Polym Phys 1991, 29, 819.
10. Baltá Calleja, F. J.; Cagiao, M. E.; Adhikari, R.; Michler, G. H. Polymer 2004, 45, 247.

11. Rueda, D. R.; Bayer, R. K.; Baltá Calleja, F. J. J Macromol Sci Phys 1989, B28, 267.

12. Perrin, F. X.; Nguyen, V.; Vernet, J. L. Polymer 2002, 43, 6159.

13. Katare, R.; Bajpai, R.; Datt, S. C. Polym Test 1991, 10, 139.

14. Baltá Calleja, F. J.; Fakirov, S. Microhardness of Polymers; Cambridge University Press: Cambridge, 2000.

15. Fakirov, S.; Krumova, M.; Rueda, D. R. Polymer 2000, 41, 3047.

16. Boyanova, M.; Fakirov, S. Polymer 2004, 45, 2093.

17. Minkova, L.; Peneva, Y. Polymer 2003, 44, 6483.

18. Kajaks, J.; Flores, A.; Garcia Gutierrez, M. C.; Rueda, D. R.; Baltá Calleja, F. J. Polymer 2000, 41, 7769.

19. Wang, X. D.; Masilamani, N. S.; Mabrey, J. D.; Alder, M. E.; Agrawal, C. M. Bone 1998, 23, 67.

20. Fini, M.; Giavaresi, G.; Greggi, T.; Martín, L.; Aldini, N. N.; Parisini, P.; Giardino, R. J Biomed Mater Res A 2003, 66, 176.

21. Giavaresi, G.; Fini, M.; Cigada, A.; Chiesa, R.; Rondelli, G.; Rimondini, L.; Aldini, N. N.; Martín, L.; Giardino, R. J Biomed Mater Res A 2003, 67, 112.

22. Takeuchi, K.; Saruwatari, L.; Nakamura, H. K.; Yang, J. M.; Ogawa, T. J Biomed Mater Res A 2005, 72, 296.

23. Ohya, S.; Kidoaki, S.; Matsouda, T. Biomaterials 2005, 26, 3105.

24. Ratner, B. D.; Chilkoti, A.; Castner, D. G. Clin Mater 1992, 11, 25.

25. Wang, Y.; Mano, J. F. J Appl Polym Sci 2006, 100, 2628.

26. Watanabe, Y.; Iwamoto, T.; Teramoto, A.; Abe, K.; Ohkoshi, Y. Mater Trans 2004, 45, 1005.

27. Li, S.; Garreau, H.; Vert, M. J Mater Sci Mater Med 1990, 1, 198.

28. Wright-Charlesworth, D. D.; Miller, D. M. Miskioglu, I.; King, J. A. J Biomed Mater Res A 2005, 74, 388.

29. Kokubo, T.; Kushitani, H.; Sakka, S.; Yamamuro, I. J Biomed Mater Res 1990, 24, 721.

30. Ward, I. M.; Hadley, D. W. An Introduction to the Mechanical Properties of Solid Polymers; Wiley: New York, 1993.

31. Auras, R.; Harte, B.; Selke, S. Macromol Biosci 2004, 4, 835.

32. Daniels, A. U.; Chang, M. K.; Andriano, K. P. J Appl Biomater 1990, 1, 57.

33. Miller, D. M. Ph.D. Thesis; Michigan Technological University: Houghton, MI, 2004.

34. Li, S. M.; Garreau, H.; Vert, M. J Mater Sci: Mater Med 1990, 1, 131.

35. Tsuji, H.; Mizuno, A.; Ikada, Y. J Appl Polym Sci 2000, 77, 1452

36. Nakamura, T.; Hitomi, S.; Watanabe, S.; Shimizu, Y.; Jamshidi, K.; Hyon, S.-H.; Ikada, Y. J Biomed Mater Res 1989, 23, 1115.

37. Pistner, H.; Bendix, D. R.; Muhling, J.; Reuther, J. F. Biomaterials 1993, 14, 291.

38. Gonzalez, M. F.; Ruseckate, R.A.; Cuadrado, T. R. J Appl Polym Sci 1999, 71, 1223.

39. Fischer, E. W.; Sterzel, H. J.; Wegner, G. Kolloid Z Z Polym 1973, 251, 980 .

40. Migliareshi, C.; Fambri, L.; Cohn, D. J Biomater Sci Polym Ed 1994, 5, 591.

41. Duek, E. A. R.; Zavaglia, C. A. C.; Belangero, W. D. Polymer 1990, 40, 465.

42. You, Y.; Min, B.-M.; Lee, S. J.; Lee, T. S.; Park, W. H. J Appl Polym Sci 2005, 95, 193.

43. Leenslag, J. W.; Pennings, A. J.; Bos, R. R. M.; Rozema, F. R.; Boering, G. Biomaterials 1987, 8, 311.

44. Wang, Y.; Gómez Ribelles, J. L.; Salmerón Sánchez, M.; Mano, J. F. Macromolecules 2005, 38, 4712

45. Alves, N. M.; Mano, J. F.; Balaguer, E.; Meseguer Dueñas, J. M.; Gómez Ribelles, J. L. Polymer 2002, 43, 4111.

46. Mano, J. F.; Gómez Ribelles, J. L.; Alves, N. M.; Salmerón Sanchez, M. Polymer 2005, 46, 8258. 